\title{
GLOBALIZAÇÃO E RISCOS AMBIENTAIS E ECOLÓGICOS: CONSEQUÊNCIAS DA SOCIEDADE MODERNA
}

\author{
GLOBALIZATION AND ENVIRONMENTAL AND ECOLOGICAL RISKS: THE \\ CONSEQUENCES OF MODERN SOCIETY
}

\author{
Sonia Aparecida de Carvalho ${ }^{1}$ \\ Liton Lanes Pilau Sobrinho² \\ Fabiola Wust Zibetti ${ }^{3}$
}

\begin{abstract}
SUMÁRIO: Introdução; Considerações Iniciais; 10 desenvolvimento dos riscos ambientais e ecológicos; 2 Os riscos ambientais e ecológicos como consequências da ação humana e da modernidade; 3 Os efeitos colaterais globais dos riscos e da globalização; Considerações Finais; Referências das Fontes Citadas
\end{abstract}

\section{RESUMO}

O objetivo geral do artigo propõe investigar os processos da globalização e os riscos ambientais e ecológicos como consequências da sociedade moderna, no âmbito local e global. Os objetivos específicos do artigo propõem pesquisar o desenvolvimento dos riscos ambientais, ecológicos, sociais, econômicos e políticos e os efeitos causados no ser humano e no meio ambiente; estudar os

\footnotetext{
1 Doutoranda em Ciência Jurídica pela Universidade do Vale do Itajaí - UNIVALI - SC. Doctoranda en Derecho pela Universidad de Alicante - UA - Espanha. Mestra em Direito pela Universidade de Santa Cruz do Sul - UNISC - RS. Professora na Universidade de Passo Fundo - UPF - RS. E-mail: sonia.adv.2008@hotmail.com.

2 Doutor em Direito pela Universidade do Vale do Rio dos Sinos - UNISINOS - RS. Professor na Universidade do Vale do Itajaí - UNIVALI - SC. Professor na Universidade de Passo Fundo - UPF RS. E-mail: liton@univali.br.

3 Doutora em Direito Internacional, pela Faculdade de Direito da Universidade de São Paulo (USP), com Pós-Doutorado pelo Programa da Pós-Graduação em Direito da Universidade Federal de Santa Catarina (UFSC) e pelo Centro Ibero-Americano, vinculado ao Instituto de Relações Internacionais da USP. Mestre em Direito, Área de Relações Internacionais, pela UFSC. Especialista em Direito Empresarial pela UFSC. Diplomas em Propriedade Industrial, em Direitos Autorais e em Análise Econômica do Direito, pela Universidade de Buenos Aires. Foi analista de Relações Internacionais da FIESP e Coordenadora de Inovação do Senac - Sistema Fecomércio-RS. Professora Convidada da Universidade de Passo Fundo (UPF) (Brasil), do Instituto de Estudios Internacionales, da Universidad de Chile, e da Universidad Mayor (Chile). Tem experiência nas áreas de direito internacional, comércio internacional, propriedade intelectual e inovação. E-mail: fwzibetti@gmail.com.
} 
CARVALHO, Sonia Aparecida de; SOBRINHO, Liton Lanes Pilau; ZIBETTI, Fabiola Wust. Globalização E Riscos Ambientais E Ecológicos: Consequências Da Sociedade Moderna. Revista Eletrônica Direito e Política, Programa de Pós-Graduação Stricto Sensu em Ciência Jurídica da UNIVALI, Itajaí, v.12, n.3, $3^{\circ}$ quadrimestre de 2017. Disponível em: www.univali.br/direitoepolitica - ISSN 1980-7791

riscos ambientais e ecológicos como consequências da ação humana, da atividade industrial e da modernidade e; analisar os efeitos colaterais globais dos riscos e da globalização e a ausência do poder soberano do Estado-nação. Na investigação do artigo, adotou-se o método indutivo, instrumentalizado com as técnicas do referente, da categoria, do conceito operacional e da pesquisa bibliográfica.

PALAVRAS-CHAVE: Globalização; Riscos ambientais e ecológicos; Modernidade

\section{ABSTRACT}

The general objective of the article is to investigate the processes of globalization and environmental and ecological risks as a consequence of modern society at the local and global levels. The specific objectives of the article propose to investigate the development of the environmental, ecological, social, economic and political risks and the effects caused in the human being and in the environment; study environmental and ecological risks as a consequence of human action, industrial activity and modernity; analyze the global collateral effects of risks and globalization in the face of the sovereign power of the nationstate. In the investigation of the article, the inductive method, instrumented with the techniques of the referent, the category, the operational concept and the bibliographic research was adopted.

KEYWORDS: Globalization; Environmental and ecological risks; Modernity

\section{INTRODUÇÃo}

O artigo objetiva investigar a os processos da globalização e os riscos ambientais e ecológicos como consequências da sociedade moderna, no âmbito local e global. Nessa perspectiva, este artigo propõe questionar os efeitos colaterais globais dos processos da globalização no desenvolvimento dos riscos, em escala mundial.

Inicialmente, o artigo divide-se em três etapas; a primeira etapa pesquisa o desenvolvimento dos riscos ambientais, ecológicos, sociais, econômicos e políticos e os efeitos causados no ser humano e no meio ambiente.

Posteriormente, a segunda etapa estuda os riscos ambientais e ecológicos como consequências da ação humana, atividade industrial e produtiva e da modernidade, e a transformação da sociedade industrial para a sociedade de risco. 
CARVALHO, Sonia Aparecida de; SOBRINHO, Liton Lanes Pilau; ZIBETTI, Fabiola Wust. Globalização E Riscos Ambientais E Ecológicos: Consequências Da Sociedade Moderna. Revista Eletrônica Direito e Política, Programa de Pós-Graduação Stricto Sensu em Ciência Jurídica da UNIVALI, Itajaí, v.12, n.3, $3^{\circ}$ quadrimestre de 2017. Disponível em: www.univali.br/direitoepolitica - ISSN 1980-7791

E finalmente, a terceira etapa analisa os efeitos colaterais globais dos riscos na sociedade de risco e nos sistemas institucionais e, o poder do processo multidimensional e transnacional da globalização na soberania do Estado-nação.

Por fim, na investigação do artigo, adotou-se o método indutivo, instrumentalizado com as técnicas do referente, da categoria, do conceito operacional e da pesquisa bibliográfica. ${ }^{4}$

\section{O DESENVOLVIMENTO DOS RISCOS AMBIENTAIS E ECOLÓgICOS}

A humanidade ou a sociedade moderna convive com a insegurança da imprevisibilidade das questões ecológicas e ambientais decorrente das ameaças causadas pelo desenvolvimento a qualquer custo, sem qualquer respeito à utilização, proteção e preservação dos recursos naturais. Trata-se da sociedade de risco, em que a produção de riquezas acarreta a produção de perigos, e sua dimensão contém efeitos, em domínio local, regional e global.

Os seres humanos sempre enfrentaram riscos, pois as sociedades humanas eram ameaçadas por riscos externos - perigos como secas, terremotos, escassez e tempestades provenientes do mundo natural, que não tinham relação alguma com ações humanas. Hoje, cada vez mais os seres humanos enfrentam vários tipos de riscos que são criados pelo impacto de nosso próprio conhecimento e da tecnologia sobre o mundo natural e os riscos ambientais e de saúde enfrentados pelas sociedades contemporâneas; e riscos produzidos que são o resultado de nossas próprias intervenções na natureza. ${ }^{5}$

Atualmente, o ser humano encontra-se muito vulnerável aos riscos, do risco individual da vida cotidiana ao risco coletivo da vida em grupo, tanto no âmbito local quanto global. O risco ${ }^{6}$ é indissociável da política, pois é necessário tomar

4 PASOLD, Cesar Luiz. Metodologia da Pesquisa Jurídica: teoria e prática. 12. ed. rev. São Paulo: Conceito Editorial, 2011, p. 25-105.

5 GIDDENS, Anthony. Um mundo em mudança. p. 71-72. Disponível em: https://bibliotecadafilo.files.wordpress.com/2013/11/giddens-um-mundo-em-mudanca.pdf. Acesso em: 10 dez. 2016.

6 "Risco é a percepção de um perigo possível, mais ou menos previsível por um grupo social ou por um indivíduo que tenha sido exposto a ele". VEYRET, Yvette (org.). Os riscos: o homem como agressor e vítima do meio ambiente. Tradução de Dilson Ferreira da Cruz. 2. ed. São Paulo: 
CARVALHO, Sonia Aparecida de; SOBRINHO, Liton Lanes Pilau; ZIBETTI, Fabiola Wust. Globalização E Riscos Ambientais E Ecológicos: Consequências Da Sociedade Moderna. Revista Eletrônica Direito e Política, Programa de Pós-Graduação Stricto Sensu em Ciência Jurídica da UNIVALI, Itajaí, v.12, n.3, $3^{\circ}$ quadrimestre de 2017. Disponível em: www.univali.br/direitoepolitica - ISSN 1980-7791

as decisões políticas referentes à organização do território, a apropriação dos bens e ao uso dos recursos naturais. Consequentemente, o risco é o efeito causado pela sociedade industrial ou moderna, como os fatores de risco são inúmeros, podem ser processos naturais ou consequências das atividades humanas e industriais. A sociedade moderna adquire os riscos visando ao objetivo perseguido e à obtenção dos bens comuns. ${ }^{7} \mathrm{O}$ risco surge da percepção de um perigo ou de uma ameaça possível, tanto em escala local quanto global.

Os riscos são, portanto, onipresentes para o indivíduo, para a sociedade civil, para aqueles que tomam decisões e mais largamente para os políticos. [...] Hoje em dia, a política não é nada mais que a gestão dos riscos, que o risco torna-se um dos fundamentos da análise política global. ${ }^{8}$

Deste modo, o risco se define como a percepção do perigo, da catástrofe e ameaça possível, pois ele é assumido, presumível e avaliado. A gestão dos riscos ambientais, ecológicos, econômicos e sociais, é indissociável das decisões políticas, atinente à organização do território. Também, "os perigos situam-se na fronteira entre o risco e a incerteza, é difícil atribuir-lhes mais do que probabilidades extremamente vagas". ${ }^{9}$ Os riscos decorrem do novo estilo e modelo de sociedade, pois é difícil avaliar o risco, inclusive os perigos causados pelo aquecimento global e pelas mudanças climáticas. As mudanças climáticas podem ter consequências catastróficas para o planeta Terra, consequentemente, a sociedade precisa conter a probabilidade dos perigos e riscos.

Do mesmo modo, os inúmeros fatores de risco, tais como os riscos ambientais, econômicos e sociais, interagem uns com os outros, no âmbito local e global. Os riscos ambientais "resultam da associação entre os riscos naturais ${ }^{10}$ e os riscos decorrentes de processos naturais agravados pela atividade humana e pela

Contexto, 2015, p. 24.

7 VEYRET, Yvette (org.). Os riscos: o homem como agressor e vítima do meio ambiente. Tradução de Dilson Ferreira da Cruz. 2. ed. São Paulo: Contexto, 2015, p. 23.

8 VEYRET, Yvette (org.). Os riscos: o homem como agressor e vítima do meio ambiente. p. 29.

9 GIDDENS, Anthony. A política da mudança climática. Tradução de Vera Ribeiro. Rio de Janeiro: Zahar, 2010, p. 55.

10 "Riscos naturais são aqueles que são pressentidos, percebidos e suportados por um grupo social ou um indivíduo sujeito à ação possível de um processo físico". VEYRET, Yvette (org.). Os riscos: o homem como agressor e vítima do meio ambiente. p. 64. 
CARVALHO, Sonia Aparecida de; SOBRINHO, Liton Lanes Pilau; ZIBETTI, Fabiola Wust. Globalização E Riscos Ambientais E Ecológicos: Consequências Da Sociedade Moderna. Revista Eletrônica Direito e Política, Programa de Pós-Graduação Stricto Sensu em Ciência Jurídica da UNIVALI, Itajaí, v.12, n.3, $3^{\circ}$ quadrimestre de 2017. Disponível em: www.univali.br/direitoepolitica - ISSN 1980-7791

ocupação do território". ${ }^{11}$ Os riscos naturais, assim como as catástrofes e seus efeitos estão relacionados à urbanização acelerada, ao meio ambiente degradado e ao subdesenvolvimento dos países.

Atualmente, os efeitos dos riscos são incalculáveis na origem e indeterminados nas suas consequências. "As consequências da globalização têm largo alcance, afetando praticamente todos os aspectos do mundo social. Entretanto, por ser a globalização um processo aberto e internamente contraditório, ela produz resultados que são difíceis de prever e controlar". ${ }^{12}$

Desse modo, uma das consequências da aceleração industrial e do desenvolvimento tecnológico tem sido a expansão da interferência humana na natureza. Os efeitos da interferência humana na natureza e no meio ambiente foi o início da destruição e poluição ambiental, em razão de que a causa é indeterminada e as consequências são difíceis de calcular.

No mundo globalizado, somos confrontados com o risco ecológico de diversas maneiras. A preocupação com o aquecimento global tem aumentado junto à comunidade científica nos últimos anos. [...] A temperatura da Terra tem se elevado devido ao aumento do volume de gases prejudiciais na atmosfera. As potenciais consequências globais deste aquecimento global são devastadoras: se as calotas polares continuarem a derreter como atualmente, 0 nível do mar aumentará, podendo ameaçar as terras baixas e suas populações. ${ }^{13}$

Dessa maneira, é possível distinguir três espécies de riscos globais: a primeira é "a destruição ecológica condicionada pela riqueza e pelos riscos técnicos industriais, como a camada de ozônio, o efeito estufa, além das consequências imprevisíveis e incalculáveis" da tecnologia; a segunda é "a destruição ecológica condicionada pela pobreza e os riscos técnicos industriais" e; a terceira é "os

11 VEYRET, Yvette (org.). Os riscos: o homem como agressor e vítima do meio ambiente. Tradução de Dilson Ferreira da Cruz. 2. ed. São Paulo: Contexto, 2015, p. 63.

12 GIDDENS, Anthony. Um mundo em mudança. p. 71. Disponível em: https://bibliotecadafilo.files.wordpress.com/2013/11/giddens-um-mundo-em-mudanca.pdf. Acesso em: 10 dez. 2016.

13 GIDDENS, Anthony. Um mundo em mudança. p. 72. 
CARVALHO, Sonia Aparecida de; SOBRINHO, Liton Lanes Pilau; ZIBETTI, Fabiola Wust. Globalização E Riscos Ambientais E Ecológicos: Consequências Da Sociedade Moderna. Revista Eletrônica Direito e Política, Programa de Pós-Graduação Stricto Sensu em Ciência Jurídica da UNIVALI, Itajaí, v.12, n.3, $3^{\circ}$ quadrimestre de 2017. Disponível em: www.univali.br/direitoepolitica - ISSN 1980-7791

riscos das armas de alto poder destrutivo", ${ }^{14}$ os riscos de autodestruição local ou global, pelas armas químicas, nucleares e tecnológicas.

Os riscos ambientais são difusos em sua origem, não se sabe como devem ser enfrentados ou quem tem a responsabilidade de agir para enfrentar os efeitos dos riscos. Os riscos ambientais ultrapassam fronteiras, pois a extensão da causa e da consequência é desconhecida e indefinida. O risco pode ser individual ou coletivo, pois a cada instante da vida podem sobrevir ameaças ou perigos e, ele está associado às diversas atividades executadas pelo ser humano. Consequentemente, os riscos e perigos são percebidos em escala planetária, causando a destruição do meio ambiente e da humanidade.

Os riscos não estão restritos: espacial, temporal ou socialmente. Os riscos de hoje afetam todos os países e todas as classes sociais. Suas consequências não são meramente pessoais, e sim globais. Muitas formas de risco produzido, tais como aquelas que dizem respeito à saúde humana e ao meio ambiente, cruzam as fronteiras nacionais. ${ }^{15}$

Os riscos ambientais e ecológicos são considerados como dano ambiental possível, futuro e incerto, pois há ameaça de dano e risco. O dano ambiental é o resultado do desequilíbrio na relação entre o ser humano e o meio ambiente e natureza, também, o dano ambiental é a lesão aos recursos naturais, com consequente degradação e alteração do equilíbrio ecológico e da qualidade de vida. Deste modo, o dano ambiental e ecológico degrada o meio ambiente, os recursos ambientais e seus elementos naturais.

O risco refere-se à iminência de um possível dano, pois está associado à possibilidade de ocorrer dano, já o dano ambiental está relacionado com o meio ambiente. O risco ambiental está relacionado com os danos que podem surgir por fatores do meio, podendo ser próprios da natureza ou provocados pelo ser humano. A atividade antrópica e produtiva ou econômica e a localização geográfica são questões que causam situações de risco ambiental, tanto a uma

${ }^{14}$ BECK, Ulrich. O que é globalização? Equívocos do globalismo: respostas à globalização. Tradução de André Carone. São Paulo: Paz e Terra, 1999, p. 79-81.

15 GIDDENS, Anthony. Um mundo em mudança. 
CARVALHO, Sonia Aparecida de; SOBRINHO, Liton Lanes Pilau; ZIBETTI, Fabiola Wust. Globalização E Riscos Ambientais E Ecológicos: Consequências Da Sociedade Moderna. Revista Eletrônica Direito e Política, Programa de Pós-Graduação Stricto Sensu em Ciência Jurídica da UNIVALI, Itajaí, v.12, n.3, $3^{\circ}$ quadrimestre de 2017. Disponível em: www.univali.br/direitoepolitica - ISSN 1980-7791

pessoa ou a um grupo de indivíduos. ${ }^{16}$ Portanto, o risco é a probabilidade de perigo, com ameaça para o homem ou ser humano e para o meio ambiente, é a possibilidade de ocorrência de um determinado evento perigoso.

\section{OS RISCOS AMBIENTAIS E ECOLÓGICOS COMO CONSEQUÊNCIAS DA AÇÃO HUMANA E DA MODERNIDADE ${ }^{17}$}

As consequências da modernização são sintomas e causas da crise ambiental e ecológica, como também, são sinais e efeitos do colapso na esfera local e global. A crise ambiental e ecológica surgiu do modelo econômico adotado, voltado para acumulação de riquezas e lucro e, para extração e exploração de recursos naturais, causando a escassez de recursos naturais e a degradação e poluição ambiental, ocasionando espécies de riscos globais. Em razão do avanço da globalização, do desenvolvimento industrial, produtivo e tecnológico, aumentam os riscos ambientais globais.

Contudo, existe uma relação intrínseca entre a destruição ambiental e a pobreza, pois "a desigualdade é o problema ambiental mais importante do planeta; é também o seu maior problema no rumo do desenvolvimento". 18 Consequentemente, para conseguir o desenvolvimento, todos os fatores sociais, econômicos, ambientais, ecológicos, culturais e políticos estão interligados e não podem ser tratados separadamente, tanto na esfera local quanto global. Entretanto, existe uma diferença entre a destruição ambiental como resultado de bem estar da coletividade e a destruição ambiental como resultado de pobreza da sociedade.

Enquanto muitos dos danos ecológicos condicionados pela riqueza são os produtos da externalizacão dos custos de produção, no caso dos danos ecológicos condicionados pela pobreza trata-se de uma autodestruição ao dos pobres que

16 Disponível em: http://conceito.de/risco-ambiental. Acesso em: 10 set. 2017.

17 A modernidade "refere-se a estilo, a costume de vida ou organização social que emergiram na Europa a partir do século XVIII e que ulteriormente se tornaram mais ou menos mundiais em sua influência". GIDDENS, Anthony. As consequências da modernidade. Tradução de Raul Fiker. São Paulo: Unesp, 1991, p. 31-32.

18 BECK, Ulrich. O que é globalização? Equívocos do globalismo: respostas à globalização. p. 80. 
CARVALHO, Sonia Aparecida de; SOBRINHO, Liton Lanes Pilau; ZIBETTI, Fabiola Wust. Globalização E Riscos Ambientais E Ecológicos: Consequências Da Sociedade Moderna. Revista Eletrônica Direito e Política, Programa de Pós-Graduação Stricto Sensu em Ciência Jurídica da UNIVALI, Itajaí, v.12, n.3, $3^{\circ}$ quadrimestre de 2017. Disponível em: www.univali.br/direitoepolitica - ISSN 1980-7791

tem efeitos colaterais para os riscos. [...] As destruições ambientais condicionadas pela riqueza se distribuem de maneira equânime pelo globo, enquanto as destruições ambientais condicionadas pela pobreza incidem sob uma mesma e única região e se intercionalizam em médio prazo sob a forma de efeitos colaterais. ${ }^{19}$

Assim sendo, existem ameaças e riscos que estão vinculados à destruição ambiental e ecológica e aos perigos tecnológico-industriais motivados pela riqueza e bem-estar, como também, existem ameaças e riscos que estão diretamente ligados à pobreza, pois há uma estreita vinculação entre a pobreza e a degradação ambiental.

Entre a destruição ambiental como resultado de bem-estar e a destruição ambiental como resultado da pobreza existe, no entanto, uma diferença essencial. Enquanto as ameaças ambientais causadas pela riqueza deriva da externalização dos custos de produção, no caso de destruição ecológica motivadas pela pobreza são os pobres que se destroem a si mesmos com efeitos colaterais para os ricos. [...] A destruição ambiental causada pela riqueza é distribuída igualmente por todo o mundo, enquanto a destruição ambiental causada pela pobreza atinge locais específicos e só se internacionaliza na forma de efeitos colaterais que ocorrem no médio prazo. ${ }^{20}$

Também, os efeitos da globalização estão ligados com os riscos ambientais e naturais. É possível diferenciar os riscos em dois tipos distintos, o risco exterior ou externo e o risco provocado. O risco exterior ou externo é aquele chega de fora imposto pela natureza, causado pelas imposições naturais. O risco provocado ou criado é aquele resultante do impacto do desenvolvimento tecnológico sobre o meio ambiente, resultante do impacto das atividades

${ }^{19}$ BECK, Ulrich. O que é globalização? Equívocos do globalismo: respostas à globalização. p. 80-81.

20 Tradução livre do trecho: "Entre la destrucción medioambiental como resultado del bienestar y la destrucción medioambiental como resultado de la pobreza existe, sin embargo, una diferencia esencial. Mientras que las amenazas ecológicas causadas por la riqueza se derivan de la exteriorización de los costes de producción, en el caso de la destrucción ecológica motivada por la pobreza son los pobres quienes se destruyen a sí mismos con efectos colaterales para los ricos. [...] La destrucción medioambiental causada por la riqueza se distribuye igualitariamente en todo el mundo, mientras que la destrucción medio ambiental causada por la pobreza golpea en lugares concretos y sólo se internacionaliza en forma de efectos colaterales que se manifiestan a medio plazo". BECK, Ulrich. La sociedad del riesgo global. Traducción de Jesús Alborés Rey. 2. ed. Madrid: Siglo XXI de España Editores S.A, 2009, p. 54-55. (grifos do autor). 
CARVALHO, Sonia Aparecida de; SOBRINHO, Liton Lanes Pilau; ZIBETTI, Fabiola Wust. Globalização E Riscos Ambientais E Ecológicos: Consequências Da Sociedade Moderna. Revista Eletrônica Direito e Política, Programa de Pós-Graduação Stricto Sensu em Ciência Jurídica da UNIVALI, Itajaí, v.12, n.3, $3^{\circ}$ quadrimestre de 2017. Disponível em: www.univali.br/direitoepolitica - ISSN 1980-7791

antrópicas. ${ }^{21}$ Desse modo, "muitos dos riscos ambientais, como os relacionados com o aquecimento global, pertencem a este tipo de risco. São influenciados diretamente pela globalização". ${ }^{22}$

A diferenciação entre o risco exterior ou externo e o provocado ou criado aponta uma distinção entre o risco e o perigo. "O risco não é o mesmo que acaso ou perigo. O risco refere-se a perigos calculados em função de possibilidades futuras". ${ }^{23}$ Dessa forma, "a noção de risco, devo acentuar, é inseparável das ideias de probabilidade e de incerteza. Não se pode dizer que alguém enfrenta um risco quando o resultado da ação está totalmente garantido". ${ }^{24}$ O risco provoca possibilidade e incerteza, pois o risco provocado ou criado não afeta apenas a natureza e o meio ambiente, mas afeta todas as espécies de vida do planeta Terra. No que se refere aos riscos incertos ou:

Quando os riscos são desconhecidos, e não podem ser estimados subjetivamente, outros instrumentos têm sido aplicados. [...] É possível aplicar diversos instrumentos de política ambiental em situações diferentes, dependendo de ser conhecida ou não a distribuição da probabilidade dos riscos. ${ }^{25}$

A sociedade moderna deve perceber que o ser humano influência no meio ambiente e natureza, e que ele é parte integrante do meio ambiente natural e não pode ser isolado de seu entorno. Também, ele sofre com os resultados de suas próprias ações, na medida em que os recursos naturais e ambientais não podem ser percebidos como um meio para que o ser humano atinja seus fins econômicos.

$\mathrm{Na}$ modernidade avançada, a sociedade com todos os seus sistemas parciais (economia, política, família, cultura) já não pode ser compreendida de uma forma autônoma em relação à natureza. Os problemas do meio ambiente não

${ }^{21}$ GIDDENS, Anthony. O mundo na era da globalização. Tradução de Saul Barata. Lisboa: Editorial Presença, 2000, p. 35.

22 GIDDENS, Anthony. 0 mundo na era da globalização. p. 35.

${ }^{23}$ GIDDENS, Anthony. 0 mundo na era da globalização. p. 33.

${ }^{24}$ GIDDENS, Anthony. 0 mundo na era da globalização. p. 32.

25 ALIER, Joan Martínez. O ecologismo dos pobres: conflitos ambientais e linguagens de valoração. Tradução de Maurício Waldman. 2. ed. São Paulo: Contexto, 2012, p. 252. 
CARVALHO, Sonia Aparecida de; SOBRINHO, Liton Lanes Pilau; ZIBETTI, Fabiola Wust. Globalização E Riscos Ambientais E Ecológicos: Consequências Da Sociedade Moderna. Revista Eletrônica Direito e Política, Programa de Pós-Graduação Stricto Sensu em Ciência Jurídica da UNIVALI, Itajaí, v.12, n.3, $3^{\circ}$ quadrimestre de 2017. Disponível em: www.univali.br/direitoepolitica - ISSN 1980-7791

são problemas do contexto, mas (em sua gênese e em suas consequências) problemas sociais, problemas do ser humano, de sua história, de suas condições de vida, de sua relação com o mundo e a realidade, de seu ordenamento econômico, cultural e político. ${ }^{26}$

Além disso, com a destruição industrial das bases ecológicas e naturais da vida, o ser humano deve repensar a relação entre o meio ambiente e natureza e a sociedade. As destruições e as ameaças da natureza se transformam em conflitos sociais, econômicos, ambientais e políticos, as lesões das condições naturais da vida se transformam em ameaças sociais e econômicas globais. Os riscos da modernização causam destruições e ameaças na natureza e na civilização.

Os riscos gerados no nível mais avançado de desenvolvimento das forças produtivas [...] se diferenciam substancialmente das riquezas. Estes riscos causam danos sistemáticos e muitas vezes irreversíveis, muitas vezes permanecem invisíveis, são baseados em interpretações causais, que são definidos apenas em conhecimento (científico ou não científico) deles, e o conhecimento pode ser transformado, ampliado ou reduzido, dramatizado ou minimizado, [...] a uma medida especial de definição de processos sociais. Assim, os meios e as posições de definição de risco tornam-se posições sociopolíticas. ${ }^{27}$

O progresso da produção industrial deriva os riscos ambientais e ecológicos, no âmbito planetário, independentemente do local de produção, pois os riscos ambientais e ecológicos caracterizam-se pelas consequências dos danos ambientais, em escala global. Os riscos ou perigos da modernização, da

26 Tradução livre do trecho: "En la modernidad avanzada la sociedad con todos sus sistemas parciales (economía, política, familia, cultura) ya no se puede comprender de una manera autónoma respecto de la naturaleza. Los problemas del medio ambiente son problemas del entorno, sino (en su génesis y en sus consecuencias) problemas sociales, problemas del ser humano, de su historia, de sus condiciones de vida, de su referencia al mundo y a la realidad, de su ordenamiento económico, cultural y político". BECK, Ulrich. La sociedad del riesgo: hacia una nueva modernidad. Traducción de Jorge Navarro; Daniel Jiménez y Maria Rosa Borrás. Barcelona: Paidós, 2006, p. 114. (grifo do autor).

27 Tradução livre do trecho: "Los riesgos que se generan en el nivel más avanzado del desarrollo de las fuerzas productivas [...] se diferencian esencialmente de las riquezas. Estos riesgos causan daños sistemáticos y a menudo irreversibles, suelen permanecer invisibles, se basan en interpretaciones causales, por lo que sólo se establecen en el saber (científico o anticientífico) de ellos, y en el saber pueden ser transformados, ampliados o reducidos, dramatizados o minimizados, [...] en una medida especial a los procesos sociales de definición. Con ello, los medios y las posiciones de la definición del riesgo se convierten en posiciones sociopolíticas clave". BECK, Ulrich. La sociedad del riesgo: hacia una nueva modernidad. p. 28. (grifos do autor). 
CARVALHO, Sonia Aparecida de; SOBRINHO, Liton Lanes Pilau; ZIBETTI, Fabiola Wust. Globalização E Riscos Ambientais E Ecológicos: Consequências Da Sociedade Moderna. Revista Eletrônica Direito e Política, Programa de Pós-Graduação Stricto Sensu em Ciência Jurídica da UNIVALI, Itajaí, v.12, n.3, $3^{\circ}$ quadrimestre de 2017. Disponível em: www.univali.br/direitoepolitica - ISSN 1980-7791

industrialização e da produção estão associados ao progresso econômico, social, ambiental e político e aos processos dos efeitos da globalização.

A sociedade mundial de risco pode sobrevalorizar a relativa autonomia da crise ecológica e transforma-la numa perspectiva unidimensional da sociedade global. Diante desse risco, faz-se necessário ressaltar a especificidade da politização forçada de todos os campos de atuação da sociedade em função dos conflitos de risco. ${ }^{28}$

A caracterização da sociedade como uma sociedade de risco aponta para o fato de que os riscos que a sociedade contemporânea causa, sobretudo são causados da própria intervenção da sociedade humana no planeta Terra. Assim, o planeta Terra sofre os efeitos da própria intervenção que a ação humana provoca no meio ambiente e na natureza. ${ }^{29}$

Portanto, que o processo de globalização traz em si mesmo a globalização da exploração da natureza com proveitos e rejeitos distribuídos desigualmente. [...] Também, que junto com o processo de globalização há, ao mesmo tempo, a dominação da natureza e a dominação de alguns homens sobre outros homens, da cultura europeia sobre outras culturas e povos. ${ }^{30}$

A sociedade mundial de risco demonstra que a globalização ecológica representa a politização forçada da atuação da sociedade. Também a sociedade de risco evidencia que a ameaça, poluição e destruição ambiental e a crise ambiental e ecológica estão associadas com a crise política e com a ordem institucional da sociedade industrial. Portanto, os riscos da modernização colocam em perigo a natureza, o meio ambiente e o ser humano, ainda, os riscos da modernização põem em perigo a civilização e excedem os limites sociais, espaciais e temporais.

${ }^{28}$ BECK, Ulrich. O que é globalização? Equívocos do globalismo: respostas à globalização. p. 83-84. (grifos do autor).

29 GONÇALVES, Carlos Walter Porto. A globalização da natureza e a natureza da globalização. 5. ed. Rio de Janeiro: Civilização Brasileira, 2013, p. 69.

30 GONÇALVES, Carlos Walter Porto. A globalização da natureza e a natureza da globalização. p. 25. 
CARVALHO, Sonia Aparecida de; SOBRINHO, Liton Lanes Pilau; ZIBETTI, Fabiola Wust. Globalização E Riscos Ambientais E Ecológicos: Consequências Da Sociedade Moderna. Revista Eletrônica Direito e Política, Programa de Pós-Graduação Stricto Sensu em Ciência Jurídica da UNIVALI, Itajaí, v.12, n.3, $3^{\circ}$ quadrimestre de 2017. Disponível em: www.univali.br/direitoepolitica - ISSN 1980-7791

\section{OS EFEITOS COLATERAIS GLOBAIS DOS RISCOS E DA GLOBALIZAÇÃO}

A sociedade industrial ocasiona riscos calculáveis e se torna cega para a confrontação com as ameaças incalculáveis. A sociedade industrial causa cegueira para a crise institucional e política, pois "o industrialismo, em seu estágio avançado na segunda metade do século $X X$, está crescentemente produzindo efeitos que não podem mais ser abarcados ou cobertos pelo cálculo do risco". ${ }^{31}$ Contudo, a modernidade reflexiva ${ }^{32}$ ou sociedade reflexiva enfrenta a sociedade industrial e as instituições sociais e políticas que ameaçam e destroem todos os cálculos de risco, bem como afronta a antecipação das consequências e a possibilidade de controle antecipatório dos efeitos colaterais dos riscos. ${ }^{33}$

A modernização como um processo de inovação autônomo deve levar em conta a sua deterioração cujo reverso é o surgimento da sociedade de risco. Este conceito designa uma fase de desenvolvimento da sociedade moderna em que através da dinâmica de mudança de produção de riscos políticos, ecológicos e individuais escapa, cada vez em maior medida, as instituições de controle e proteção da chamada sociedade industrial. ${ }^{34}$

No conceito de sociedade de risco, a sociedade torna-se reflexiva, pois se torna um problema para ela própria. Os efeitos colaterais da produção industrial que gera a crise ambiental ou ecológica, no âmbito global, é uma crise institucional

31 BECK, Ulrich. Réplicas e críticas. In: BECK, Ulrich; GIDDENS, Anthony; LASCH, Scott (orgs.). Modernização reflexiva: política, tradição e estética na ordem social moderna. Tradução de Magda Lopes. São Paulo: Unesp, 1997, p. 215.

32 "Modernização reflexiva significa a possibilidade de uma (auto) destruição criativa para toda uma era: aquela da sociedade industrial. O sujeito dessa destruição criativa não é a revolução, não é a crise, mas a vitória da modernização". BECK, Ulrich. A reinvenção da política: rumo a uma teoria da modernização reflexiva. In: BECK, Ulrich; GIDDENS, Anthony; LASH, Scott (orgs.). Modernização reflexiva: política, tradição e estética na ordem social moderna. Tradução de Magda Lopes. São Paulo: Unesp, 1997, p. 12.

33 BECK, Ulrich. Réplicas e críticas. In: BECK, Ulrich; GIDDENS, Anthony; LASCH, Scott (orgs.). Modernização reflexiva: política, tradição e estética na ordem social moderna. p. 216.

34 Tradução livre do trecho: "La modernización como un proceso autónomo de innovación debe tener en cuenta su deterioro cuyo reverso es el surgimiento de la sociedad del riesgo. Este concepto designa una fase de desarrollo de la sociedad moderna en la que a través de la dinámica de cambio la producción de riesgos políticos, ecológicos e individuales escapa, cada vez en mayor proporción, a las instituciones de control y protección de la mentada sociedad industrial". BECK, Ulrich. La modernidad reflexiva. In: GIDDENS, Anthony; BAUMAN, Zygmunt; LUHMANN, Niklas; BECK, Ulrich (orgs.). Las consecuencias perversas de la modernidad: modernidad, contingencia y riesgo. Traducción de Celso Sánchez Capdequí. Barcelona: Editorial Anthropos, 1996 , p. 201. 
CARVALHO, Sonia Aparecida de; SOBRINHO, Liton Lanes Pilau; ZIBETTI, Fabiola Wust. Globalização E Riscos Ambientais E Ecológicos: Consequências Da Sociedade Moderna. Revista Eletrônica Direito e Política, Programa de Pós-Graduação Stricto Sensu em Ciência Jurídica da UNIVALI, Itajaí, v.12, n.3, $3^{\circ}$ quadrimestre de 2017. Disponível em: www.univali.br/direitoepolitica - ISSN 1980-7791

da própria sociedade industrial. Na sociedade moderna, cada vez mais os conflitos sociais não são mais tratados como problemas de ordem, mas como problemas de risco. "Os problemas de risco são caracterizados por não terem soluções ambíguas; ao contrário, são distinguidos por uma ambivalência, [...] compreendida por cálculos de probabilidade",35 pois é sua ambivalência que distingue os problemas de risco dos problemas de ordem.

O controle antecipatório dos efeitos colaterais da globalização e dos riscos da modernidade é incontrolável, pois "os riscos são uma tentativa de tornar calculável o incalculável", e uma tentativa de tornar "os acontecimentos que ainda não ocorreram tornam-se calculável". ${ }^{36}$ Os efeitos colaterais negativos da globalização e dos riscos desvalorizam o capital, provocam o colapso dos mercados e da economia e geram as catástrofes ambientais e ecológicas, tais como as mudanças climáticas e o aquecimento global. ${ }^{37}$

Os riscos na sociedade industrial caracterizam-se por sua previsão e limitação espacial, temporal e social, devido à restrição da dimensão do dano, em determinado local ou espaço do globo. Já, os riscos na sociedade de risco caracterizam-se por sua ilimitação espacial, temporal e social, devido à irrestrição da dimensão do dano, em indeterminado local ou espaço, afetando todos os lugares do globo. Também, a extensão do dano afeta todos aqueles que produzem na forma de um efeito social bumerangue, pois a dimensão do risco não pode ser delimitada, tornado difícil o seu controle e seus efeitos colaterais. ${ }^{38}$

Inserido na globalização e, não obstante, claramente diferente dela, é um modelo de compartilhamento dos riscos, em que se inclui uma boa quantidade de dinamite política: os riscos afetam mais cedo ou mais tarde aqueles que os geram ou se beneficiam deles. Os riscos mostram em

35 BECK, Ulrich. A reinvenção da política: rumo a uma teoria da modernização reflexiva. In: BECK, Ulrich; GIDDENS, Anthony; LASH, Scott (orgs.). Modernização reflexiva: política, tradição e estética na ordem social moderna. p. 19.

36 BECK, Ulrich. Réplicas e críticas. In: BECK, Ulrich; GIDDENS, Anthony; LASCH, Scott (orgs.). Modernização reflexiva: política, tradição e estética na ordem social moderna. p. 215.

37 BECK, Ulrich. Réplicas e críticas. In: BECK, Ulrich; GIDDENS, Anthony; LASCH, Scott (orgs.). Modernização reflexiva: política, tradição e estética na ordem social moderna. p. 214.

38 BECK, Ulrich. La sociedad del riesgo: hacia una nueva modernidad. Traducción de Jorge Navarro; Daniel Jiménez y Maria Rosa Borrás. Barcelona: Paidós, 2006, p. 52. 
CARVALHO, Sonia Aparecida de; SOBRINHO, Liton Lanes Pilau; ZIBETTI, Fabiola Wust. Globalização E Riscos Ambientais E Ecológicos: Consequências Da Sociedade Moderna. Revista Eletrônica Direito e Política, Programa de Pós-Graduação Stricto Sensu em Ciência Jurídica da UNIVALI, Itajaí, v.12, n.3, $3^{\circ}$ quadrimestre de 2017. Disponível em: www.univali.br/direitoepolitica - ISSN 1980-7791

sua propagação um efeito social de bumerangue: nem os ricos tampouco os poderosos estão seguros diante deles. [...] Os próprios atores da modernização caem de uma forma enfática e muito concreta no redemoinho dos perigos que desencadeiam e dos que se beneficiam deles. ${ }^{39}$

Igualmente, os riscos surgem de situações sociais de ameaças e perigos, como também, "os riscos da modernização afetam mais tarde ou mais cedo, também para aqueles que produzem ou beneficiam deles". ${ }^{40}$ Os riscos produzem um efeito social bumerangue, "tampouco os ricos e poderosos estão seguros diante deles". ${ }^{41}$ Ao mesmo tempo, os riscos produzem desigualdades sociais, econômicas e ambientais, entre os países industrializados ou desenvolvidos e os países em desenvolvimento.

A globalização é normalmente associada a processos econômicos, como a circulação de capitais, a ampliação dos mercados ou a integração produtiva em escala mundial. Mas também, é um fenômeno da esfera social, como a criação e expansão de instituições supranacionais e a universalização dos padrões culturais. ${ }^{42}$

A globalização ocasiona a transformação espacial e temporal da economia mundial. Ainda, entre os processos não econômicos, a globalização é associada às questões referentes do planeta Terra, como a proteção do meio ambiente, a expansão da democracia, sobretudo, a deterioração ecológica do planeta Terra. Assim, a globalização é a transnacionalização das relações econômicas, sociais, politicas e culturais que ocorrem no mundo. ${ }^{43}$ "As principais transformações

\footnotetext{
39 Tradução livre do trecho: "Contenido en la globalización y sin embargo claramente diferente de ella es un modelo de reparto de los riesgos en el que se encierra una buena cantidad de dinamita política: los riesgos afectan más tarde o más temprano a quienes los producen o se benefician de ellos. Los riesgos muestran en su difusión un efecto social de bumerang: tampoco los ricos y los poderosos están seguros ante ellos. [...] Los propios actores de la modernización caen de una manera enfática y muy concreta en el remolino de los peligros que desencadenan y los que se benefician". BECK, Ulrich. La sociedad del riesgo: hacia una nueva modernidad. p. 53. (grifos do autor).

40 Tradução livre do trecho: "los riesgos de la modernización afectan más tarde o más temprano, también a quienes los producen o se benefician de ellos". BECK, Ulrich. La sociedad del riesgo: hacia una nueva modernidad. p. 34.

41 Tradução livre do trecho: "tampoco los ricos y poderosos están seguros ante ellos". BECK, Ulrich. La sociedad del riesgo: hacia una nueva modernidad. p. 34.
}

42 VIEIRA, Liszt. Cidadania e globalização. 12. ed. Rio de Janeiro: Record, 2013, p. 72-73.

43 VIEIRA, Liszt. Cidadania e globalização. p. 73. 
CARVALHO, Sonia Aparecida de; SOBRINHO, Liton Lanes Pilau; ZIBETTI, Fabiola Wust. Globalização E Riscos Ambientais E Ecológicos: Consequências Da Sociedade Moderna. Revista Eletrônica Direito e Política, Programa de Pós-Graduação Stricto Sensu em Ciência Jurídica da UNIVALI, Itajaí, v.12, n.3, $3^{\circ}$ quadrimestre de 2017. Disponível em: www.univali.br/direitoepolitica - ISSN 1980-7791

acarretadas pela globalização são no âmbito da organização econômica, das relações sociais, dos padrões de vida e cultura". ${ }^{44} \mathrm{Na}$ era moderna, o nível de distanciamento de tempo e de espaço é muito maior do que em qualquer outro período, e as relações sociais e eventos locais e distantes se tornam alongadas.

A globalização se refere essencialmente a este processo de alongamento, na medida em que as modalidades de conexão entre diferentes regiões ou contextos sociais se enredaram através da superfície da Terra como um todo. A globalização pode assim ser definida como a intensificação das relações sociais em escala mundial, que ligam localidades distantes de tal maneira que acontecimentos locais são modelados por eventos ocorrendo a muitas milhas de distância e viceversa. ${ }^{45}$

O ambiente global estabelece uma relação entre o que localizável e o que está em um espaço delimitado, é influenciado por determinados eventos ligados ao tempo e ao espaço. A globalização alonga as conexões sociais através do tempo e do espaço. ${ }^{46}$ A globalização é um processo multidimensional, que estende as relações sociais em escala mundial, no tempo e espaço, pois "os acontecimentos locais podem se deslocar numa direção anversa às relações muito distanciadas que os modelam". ${ }^{47}$ No processo de globalização, o Estado-nação está ausente para os problemas políticos, sociais, econômicos, ambientais e ecológicos, acarretando uma desordem mundial.

O processo de globalização é uma desordem mundial, já que seus efeitos são transnacionais, difíceis de identificar e controlar, tanto no domínio local quanto global. Os efeitos da globalização geram o definhamento do Estado-nação gerando uma catástrofe natural. Igualmente, as "suas causas não são plenamente compreendidas; ele não pode ser previsto com exatidão mesmo que as causas sejam conhecidas; e com certeza não pode ser evitado, mesmo que previsto". 48 Desse modo, "a globalização significa os processos pelos quais a

\footnotetext{
44 VIEIRA, Liszt. Cidadania e globalização. p. 74.

45 GIDDENS, Anthony. As consequências da modernidade. Tradução de Raul Fiker. São Paulo: Unesp, 1991, p. 69.

${ }^{46}$ GIDDENS, Anthony. As consequências da modernidade. 69.

47 GIDDENS, Anthony. As consequências da modernidade. p. 70.

48 BAUMAN, Zygmunt. Globalização: as consequências humanas. Tradução de Marcus Penchel.
} 
CARVALHO, Sonia Aparecida de; SOBRINHO, Liton Lanes Pilau; ZIBETTI, Fabiola Wust. Globalização E Riscos Ambientais E Ecológicos: Consequências Da Sociedade Moderna. Revista Eletrônica Direito e Política, Programa de Pós-Graduação Stricto Sensu em Ciência Jurídica da UNIVALI, Itajaí, v.12, n.3, $3^{\circ}$ quadrimestre de 2017. Disponível em: www.univali.br/direitoepolitica - ISSN 1980-7791

soberania dos Estados nacionais está entrelaçada através de atores transnacionais e suas respectivas probabilidades de poder". 49

Além disso, a globalização é um processo irreversível que afeta todas as pessoas na mesma medida e da mesma maneira, ao mesmo tempo e espaço. As causas e efeitos dos processos da globalização não têm efeitos iguais, pois os usos do tempo e do espaço são desiguais no mundo. "A globalização tanto divide como une; divide enquanto une, e as causas da divisão são idênticas às que promovem a uniformidade do globo".50 A globalização "refere-se aos efeitos globais, notoriamente não pretendidos e imprevistos. [...] Refere-se às forças anônimas [...] que se estende para além do alcance da capacidade de desígnio e ação de quem que seja em particular". ${ }^{51}$

Nesse sentido, a "globalização significa a experiência cotidiana da ação sem fronteiras nas dimensões da economia, da informação, da ecologia, da técnica, dos conflitos transculturais e da sociedade civil". ${ }^{52}$ A globalização é um processo multidimensional, de natureza econômica, social e política, que se caracteriza pelo enfraquecimento da soberana dos Estados nacionais. Nesse sentido, surge uma sociedade mundial, sem um Estado transnacional e um governo transnacional.

A globalização também significa a ausência do Estado mundial. Mais precisamente: sociedade mundial sem Estado mundial e sem governo mundial. Está se disseminando um capitalismo global desorganizado, pois não há poder hegemônico ou regime internacional econômico ou político. ${ }^{53}$

Rio de Janeiro: Zahar, 1999, p. 65.

49 Tradução livre do trecho: "la globalización significa los procesos en virtud de los cuales los Estados nacionales soberanos se entremezclan e imbrican mediante actores transnacionales $y$ sus respectivas probabilidades de poder". BECK, Ulrich. ¿Qué es la globalización? Falacias del globalismo, respuestas a la globalización. Traducción de Bernardo Moreno y María Rosa Borrás. Barcelona: Paidós, 2008, p. 34.

50 BAUMAN, Zygmunt. Globalização: as consequências humanas. Tradução de Marcus Penchel. Rio de Janeiro: Zahar, 1999, p. 8.

51 BAUMAN, Zygmunt. Globalização: as consequências humanas. p. 67-68.

52 BECK, Ulrich. O que é globalização? Equívocos do globalismo: respostas à globalização. Tradução de André Carone. São Paulo: Paz e Terra, 1999, p. 46.

53 Tradução livre do trecho: "A globalización también significa la ausencia de Estado mundial: más concretamente: sociedad mundial sin Estado mundial y sin gobierno mundial. Estamos 
CARVALHO, Sonia Aparecida de; SOBRINHO, Liton Lanes Pilau; ZIBETTI, Fabiola Wust. Globalização E Riscos Ambientais E Ecológicos: Consequências Da Sociedade Moderna. Revista Eletrônica Direito e Política, Programa de Pós-Graduação Stricto Sensu em Ciência Jurídica da UNIVALI, Itajaí, v.12, n.3, $3^{\circ}$ quadrimestre de 2017. Disponível em: www.univali.br/direitoepolitica - ISSN 1980-7791

A globalização é um fenômeno e ao mesmo tempo um processo transnacional produzido pela união de fatores sociais e econômicos. A globalização não é apenas um fenômeno de sistemas sociais e econômicos é também, um fenômeno local, um fenômeno que afeta a todos. "A globalização é um conjunto de processos imprevisíveis, é difícil de controlar e gera novos riscos que afetam a todos". ${ }^{54}$ Também, "a globalização significa que cada vez mais estamos vivendo num único mundo, em que os indivíduos, os grupos e as nações tornaram-se mais interdependentes". ${ }^{55}$ A globalização é produzida pela união de fatores políticos, econômicos, culturais e sociais. A modernização dos riscos, elementos que se encontram de forma objetiva e subjetiva, espacial e temporal separados, mantém a forma causal, ainda que de maneira incerta.

A globalização do risco pode ser vista em sua intensidade, e na expansão da quantidade de eventos que afetam todos ou a menor quantidade de pessoas no planeta Terra. [...] $\mathrm{O}$ risco trabalha com as mudanças no tipo de ambiente de risco, estabelecendo padrões tanto derivados do meio ambiente criado ou natureza socializada quanto do desenvolvimento de riscos ambientais institucionais. ${ }^{56}$

No mundo globalizado, os efeitos dos riscos ambientais locais também são globais, por isso a questão ambiental é mundial. Desse modo, os diferentes problemas, no espaço e tempo mundial, como "o aumento da população, a globalização da economia e a degradação ambiental, o espaço e tempo mundial parece defrontar-se com uma situação dilemática a vários níveis". ${ }^{57}$ A situação dilemática caracteriza-se na ausência de soberania dos Estados nacionais no desenvolvimento social, já que o modelo de desenvolvimento capitalista domina

asistiendo a la difusión de un capitalismo globalmente desorganizado, donde no existe ningún poder hegemónico ni ningún régimen internacional, ya de tipo económico ya político". BECK, Ulrich. ¿Qué es la globalización? Falacias del globalismo, respuestas a la globalización. p. 38. (grifos do autor).

54 GIDDENS, Anthony. Um mundo em mudança. p. 61. Disponível em: https://bibliotecadafilo.files.wordpress.com/2013/11/giddens-um-mundo-em-mudanca.pdf. Acesso em: 10 dez. 2016.

55 GIDDENS, Anthony. Um mundo em mudança. p. 61.

56 GUILHERME, Márcia Lúcia. Sustentabilidade sob a ótica global e local. São Paulo: Annablume; Fapesp, 2007, p. 60.

57 SANTOS, Boaventura de Sousa. Pela mão de Alice: o social e o político na pós- modernidade. 7. ed. Porto: Afrontamento, 1999, p. 258. 
CARVALHO, Sonia Aparecida de; SOBRINHO, Liton Lanes Pilau; ZIBETTI, Fabiola Wust. Globalização E Riscos Ambientais E Ecológicos: Consequências Da Sociedade Moderna. Revista Eletrônica Direito e Política, Programa de Pós-Graduação Stricto Sensu em Ciência Jurídica da UNIVALI, Itajaí, v.12, n.3, $3^{\circ}$ quadrimestre de 2017. Disponível em: www.univali.br/direitoepolitica - ISSN 1980-7791

a hegemonia global. Do mesmo modo, "o Estado-nação tornou-se demasiado pequeno para revolver os grandes problemas e ao mesmo tempo demasiado grande para resolver os pequenos". ${ }^{58}$ Os efeitos da globalização econômica gera a deficiência dos Estados nacionais, pois os fatores da crise originam fora das suas fronteiras e assumem riscos localizados, distintos, difíceis e indeterminados. ${ }^{59}$

A globalização econômica interfere na produção do risco social, com a produção de fatores que alterem a probabilidade de ocorrências de desigualdades e exclusão social. O risco social num mundo globalizado deriva do efeito sociedade moderna e de seus sistemas institucionalizados de proteção social. A globalização aumenta as desigualdades e a exclusão social gerada pelo próprio sistema capitalista, em vez de promover a sua redução. ${ }^{60}$

Os efeitos colaterais dos riscos são integrais e ilimitados e, os danos não são limitados no espaço e no tempo, pois os riscos são globais e duradouros. Portanto, o risco e a globalização são fatores que contribuem para o desenvolvimento da sociedade de risco. A sociedade de risco, não inclui somente os riscos ambientais, ecológicos e humanos, mas também, inclui riscos sociais, econômicos e políticos, originados pela sociedade contemporânea.

\footnotetext{
58 HESPANHA, Pedro. Mal estar e risco social num mundo globalizado: novos problemas e novos desafios para a teoria social. In: SANTOS, Boaventura de Sousa (org.). A globalização e as ciências sociais. 2. ed. São Paulo: Cortez, 2002, p. 174.

59 HESPANHA, Pedro. Mal estar e risco social num mundo globalizado: novos problemas e novos desafios para a teoria social. In: SANTOS, Boaventura de Sousa (org.). A globalização e as ciências sociais. p. 174.

60 HESPANHA, Pedro. Mal estar e risco social num mundo globalizado: novos problemas e novos desafios para a teoria social. In: SANTOS, Boaventura de Sousa (org.). A globalização e as ciências sociais. p. 168.
} 
CARVALHO, Sonia Aparecida de; SOBRINHO, Liton Lanes Pilau; ZIBETTI, Fabiola Wust. Globalização E Riscos Ambientais E Ecológicos: Consequências Da Sociedade Moderna. Revista Eletrônica Direito e Política, Programa de Pós-Graduação Stricto Sensu em Ciência Jurídica da UNIVALI, Itajaí, v.12, n.3, 30 quadrimestre de 2017. Disponível em: www.univali.br/direitoepolitica - ISSN 1980-7791

\section{CONSIDERAÇÕES FINAIS}

Diante dessa perspectiva, o estudo do artigo demonstra que o desenvolvimento dos riscos ambientais, ecológicos, sociais, econômicos e políticos causam efeitos negativos no ser humano e no meio ambiente, como também gera a crise no âmbito mundial.

A pesquisa do artigo evidencia que os riscos ambientais e ecológicos são consequências da ação humana, da atividade industrial e produtiva e do progresso da modernidade, transformando a sociedade industrial em uma sociedade de risco.

E por fim, o estudo do artigo comprova que os efeitos colaterais globais dos riscos na sociedade de risco, decorrem de sistemas institucionais e de processos da globalização.

A globalização é um processo multidimensional, que amplia as relações sociais, em escala mundial, no tempo e no espaço, porquanto o Estado-nação perde ou ausenta a sua soberania e o seu controle antecipatório dos efeitos colaterais dos riscos políticos, sociais, econômicos, ambientais e ecológicos, acarretando a crise global.

Portanto, a sociedade de risco não inclui somente os riscos ambientais, ecológicos, humanos e civilizatórios, mas também, inclui riscos sociais, econômicos e políticos, originados pela sociedade contemporânea ou modernidade. 


\section{REFERÊNCIAS DAS FONTES CITADAS}

ALIER, Joan Martínez. O ecologismo dos pobres: conflitos ambientais e linguagens de valoração. Tradução de Maurício Waldman. 2. ed. São Paulo: Contexto, 2012. Título original: El ecologismo de los pobres: conflictos ambientales y lenguajes de valoración.

BAUMAN, Zygmunt. Globalização: as consequências humanas. Tradução de Marcus Penchel. Rio de Janeiro: Zahar, 1999. Título original: Globalization: the human consequences.

BECK, Ulrich. O que é globalização? Equívocos do globalismo: respostas à globalização. Tradução de André Carone. São Paulo: Paz e Terra, 1999. Título original: Qué es la globalización? Falacias del globalismo, respuestas a la globalización.

¿Qué es la globalización? Falacias del globalismo, respuestas a la globalización. Traducción de Bernardo Moreno y María Rosa Borrás. Barcelona: Paidós, 2008.

. La sociedad del riesgo global. Traducción de Jesús Alborés Rey. 2. ed. Madrid: Siglo XXI de España Editores S.A, 2009. Título original: World risk society.

La sociedad del riesgo: hacia una nueva modernidad. Traducción de Jorge Navarro; Daniel Jiménez y Maria Rosa Borrás. Barcelona: Paidós, 2006. Título original: Risikogesellschaft. Auf dem weg in eine andere moderne.

Réplicas e críticas. In: ; GIDDENS, Anthony; LASCH, Scott (orgs.). Modernização reflexiva: política, tradição e estética na ordem social moderna. Tradução de Magda Lopes. São Paulo: Unesp, 1997, p. 207- 254.

A reinvenção da política: rumo a uma teoria da modernização reflexiva. In: _ ; GIDDENS, Anthony; LASH, Scott (orgs.). Modernização reflexiva: política, tradição e estética na ordem social moderna. Tradução de Magda Lopes. São Paulo: Unesp, 1997, p. 11-71.

La modernidad reflexiva. In: GIDDENS, Anthony; BAUMAN, Zygmunt; LUHMANN, Niklas; BECK, Ulrich (orgs.). Las consecuencias perversas de la modernidad: modernidad, contingencia y riesgo. Traducción de Celso Sánchez Capdequí. Barcelona: Editorial Anthropos, 1996, p. 201- 265.

Disponível em: http://conceito.de/risco-ambiental. Acesso em: 10 set. 2017.

GIDDENS, Anthony. A política da mudança climática. Tradução de Vera Ribeiro. Rio de Janeiro: Zahar, 2010.

O mundo na era da globalização. Tradução de Saul Barata. Lisboa: Editorial Presença, 2000. 
. As consequências da modernidade. Tradução de Raul Fiker. São Paulo: Unesp, 1991. Título original: The consequences of modernity.

Um mundo em mudança. p. 71-72. Disponível em: https://bibliotecadafilo.files.wordpress.com/2013/11/giddens-um-mundo-emmudanca.pdf. Acesso em: 10 dez. 2016.

GONÇALVES, Carlos Walter Porto. A globalização da natureza e a natureza da globalização. 5. ed. Rio de Janeiro: Civilização Brasileira, 2013.

GUILHERME, Márcia Lúcia. Sustentabilidade sob a ótica global e local. São Paulo: Annablume; Fapesp, 2007.

HESPANHA, Pedro. Mal estar e risco social num mundo globalizado: novos problemas e novos desafios para a teoria social. In: SANTOS, Boaventura de Sousa (org.). A globalização e as ciências sociais. 2. ed. São Paulo: Cortez, 2002, p. 161-196.

PASOLD, Cesar Luiz. Metodologia da Pesquisa Jurídica: teoria e prática. 12. ed. rev. São Paulo: Conceito Editorial, 2011.

SANTOS, Boaventura de Sousa. Pela mão de Alice: o social e o político na pósmodernidade. 7. ed. Porto: Afrontamento, 1999.

VEYRET, Yvette (org.). Os riscos: o homem como agressor e vítima do meio ambiente. Tradução de Dilson Ferreira da Cruz. 2. ed. São Paulo: Contexto, 2015. Título original: Les risques.

VIEIRA, Liszt. Cidadania e globalização. 12. ed. Rio de Janeiro: Record, 2013.

Submetido em: outubro de 2017

Aprovado em: dezembro de 2017 